\title{
BUBBLE BEHAVIOUR DURING OXYGEN AND HYDROGEN EVOLUTION AT TRANSPARENT ELECTRODES IN KOH SOLUTION
}

\author{
L. J. J. Janssen, C. W. M. P. Sillen, E. Barendrecht and S. J. D. van Stralen \\ Eindhoven University of Technology, P. O. Box 513, 5600 MB Eindhoven, The Netherlands
}

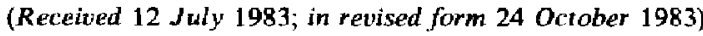

\begin{abstract}
For oxygen and hydrogen evolving transparent nickel electrodes in $\mathrm{KOH}$ solutions, parameters characterizing the behaviour of bubbles which are adhered to the electrode surface during gas evolution, have been determined in dependence on current density, $i$, velocity of solution flow, $v$, pressure, $p$, temperature, $T$, and concentration of KOH. Based on experimental data a new basic bubble parameter, $J$, has been introduced, which accounts for the bubble behaviour. It has been found that $J=a_{1} i^{h_{1}}$ and $J /\left(J_{0}-J\right)$ $=a_{2} v^{h_{2}}$ where $J_{0}=J$ at $v=0 \mathrm{~m} \mathrm{~s}^{-1}$ and $a_{1}, a_{2} h_{1}$ and $h_{2}$ are empirical constants; some of these depend on nature of gas evolved. Moreover, the parameter $J$ is almost proportional to the $\mathrm{KOH}$ concentration, increases in a decreasing rate with increasing pressure and increases linearly with the reciprocal of the absolute temperature.
\end{abstract}

\section{NOMENCLATURE}

$a_{1,2} \quad$ experimental constants

$A_{i} \quad$ surface area of observed part of the electrode for picture $i\left(\mathrm{~m}^{2}\right)$

C concentration of dissolved gas $\left(\mathrm{mol} \mathrm{m}^{-3}\right)$

Cs saturation concentration of dissolved gas $\left(\mathrm{mol} \mathrm{m}^{-3}\right)$

$\triangle C$ wall supersaturation of dissolved gas $\left(\mathrm{mol} \mathrm{m}^{-3}\right)$

$d$ average bubble population density $\left(\mathrm{m}^{-2}\right)$

$d_{i} \quad$ bubble population density for picture $i\left(\mathrm{~m}^{-2}\right)$

$D_{j} \quad$ diffusion coefficient of species $j\left(\mathrm{~m}^{2} \mathrm{~s}^{-1}\right)$

$F \quad=96.48710^{6} \mathrm{Ckmol}^{-1}$, Faraday constant

$h_{1} \quad$ slope of $\log J / \log i$ curve

$h_{2}$ slope of $\log \left(J /\left(J_{0}-J\right)\right) / \log v$ curve

$i$ electric current density; (picture number) $\left(\mathrm{A} \mathrm{m}^{-2}\right.$ ) electric current density, used for gas in bubbles $\left(\mathrm{A} \mathrm{m}^{-2}\right)$

electric current density, used for dissolved gas $\left(A \mathrm{~m}^{-2}\right)$

exchange current density $\left(\mathrm{A} \mathrm{m}^{-2}\right)$

electric current (A)

basic bubble parameter $\left(\mathrm{m}^{-1}\right)$

$J$ at $v=0 \mathrm{~m} \mathrm{~s}^{-1}\left(\mathrm{~m}^{-1}\right)$

mass transfer cofficient of species $J\left(\mathrm{~ms}^{-1}\right)$

experimental constant

experimental constant

number of bubbles at electrode surface area $A_{i}$ for, picture $i$

pressure $\left(\mathrm{N} \mathrm{m}^{-2}\right)$

average radius of attached bubbles ( $m$ )

average radius of attached bubbles for picture $i(\mathrm{~m})$ average maximum radius of attached bubbles ( $m$ )

radius of the biggest attached bubble on picture $i(\mathrm{~m})$ average degree of screening of the electrode by attached bubbles

degree of screening of the electrode by attached bubbles for picture $i$

time (s)

electrolysis time (s)

temperature $(\mathbf{K})$

liquid flow velocity $\left(\mathrm{ms}^{-1}\right)$

volumetric gas production rate $\left(\mathrm{m}^{3} \mathrm{~s}^{-1}\right)$

volume of attached bubbles per unit surface (m)

volume of attached bubbles per unit surface area for picture $i(\mathrm{~m})$

\section{INTRODUCTION}

Gas-evolving electrodes have been extensively studied during the last 20 years owing to their great interest for energy consumption and/or mass transfer in many industrial electrochemical processes.

For a better understanding of the performance of gas-evolving electrodes, the knowledge of the behaviour of bubbles present on the gas-evolving electrodes is necessary. The bubble behaviour is characterized by a set of parameters, eg radius of bubbles, degree of screening by attached bubbles, volume of attached bubbles per unit electrode surface area, bubble population density on electrode surface and bubble radius distribution function[1]. In 1982 an interesting survey on electrochemical reactors with gas evolution was published by Vogt[2]. In this survey, also already published results on bubble behaviour are discussed. More recently, Sillen[3] has published a thesis containing many experimental results about the effect of electrolytic parameters, viz current density, solution flow velocity, pressure, concentration of $\mathrm{KOH}$ and temperature on parameters characterizing the bubble behaviour.

Some of Sillen's results are used in this paper. A basic parameter having the dimensions of reciprocal length, is proposed to describe the behaviour of attached bubbles. Generally useful relations, deduced from Sillen's experimental results, are given for the effect of electrolytic parameters on the basic parameter proposed.

\section{EXPERIMENTAL}

\subsection{Electrochemical measurements}

The experiments have been carried out with an acrylate cell for atmospheric pressure and for forced and natural convection and a stainless steel electrolysis cell with transparent windows for elevated pressures 


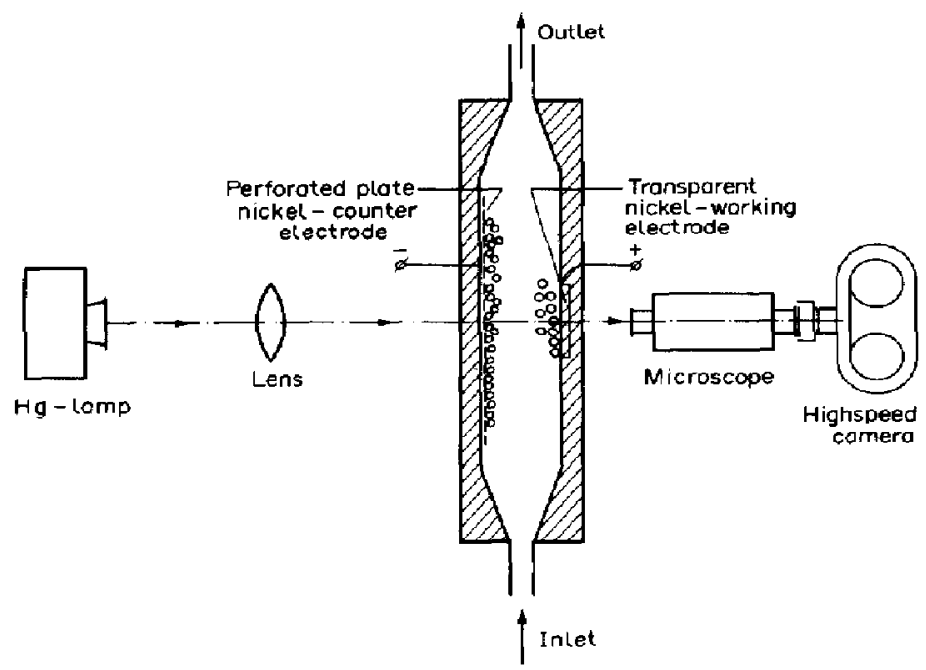

Fig. 1. Acrylate electrolysis cell used for forced flow.

and for only natural convection. The acrylate cell is sketched in Fig. 1. To obtain a parallel liquid flow and to prevent flow instabilities, a grid was placed in the cell. At forced convection, the flow circuit, given in Fig. 1 of [4] is used. The two-phase mixture degassed in the hydrocyclone. The liquid flow velocity is measured with turbine flow meters. The working electrode is an optically transparent nickel electrode with a width of $1 \mathrm{~cm}$ and a height of $3 \mathrm{~cm}$. This electrode is placed vertically. Its preparation technique and some of its properties are given in [1]; its square ohmic resistance is of the order of $10-20 \Omega$. The distance between the working clectrode and the counter electrode (a nickel perforated plate of $1 \times 10 \mathrm{~cm}^{2}$, placed symmetrically opposite the working electrodel, is approximately $4 \mathrm{~cm}$. Interactions of hydrogen and oxygen bubbles do not occur in the vicinity of one of the electrodes.

The stainless steel electrolysis cell is schematically represented in Fig. 2. This cell is only used for electrolysis under natural convection. The working electrode is an optically transparent nickel disc electrode of $3.06 \mathrm{~cm}^{2}[1]$ and is mounted in the cell as a window. Experiments have been carried out at vertically and horizontally placed working electrodes. The counter electrode is a platinum sheet of $5 \mathrm{~cm}^{2}$. Both compartments have a volume of about $1000 \mathrm{~cm}^{3}$. The produced hydrogen and oxygen are recombined at a glowing platinum wire in a recombiner. To obtain elevated pressures, the vessel was connected to a nitrogen cylinder with a high nitrogen pressure. The pressure was measured with a pressure gauge. The electrolyses have been carried out galvanostatically at a constant temperature of the electrolyte measured with a thermocouple.

The effect of current density, $i$, has been determined at decreasing $i$ at free and forced convection, both for hydrogen and oxygen evolution. The effect of forced convection has been investigated, for hydrogen evolution at one and, for oxygen evolution, at two values of $i$, at decreasing $v$.

The effect of pressure, $p$, has only been obtained at free convection, with a verfical (hydrogen and oxygen) and a horizontal electrode (oxygen only), both at decreasing $p$. Determination of the pressure influence for hydrogen evolution at a horizontal electrode was impossible because of formation of a mist of bubbles in the electrolyte above the horizontal electrode. The temperature effect has been studied experimentally at increasing and decreasing $T$ at free and forced convection, yet only for oxygen evolution. Experiments at increasing $\mathrm{KOH}$ concentration have been carried out at free (hydrogen and oxygen) and forced convection (oxygen only). Unless otherwise mentioned, the experiments have been carried out at the standard conditions of $2 \mathrm{kA} \mathrm{m}^{-2}, 303 \mathrm{~K}$ and $101 \mathrm{kPa}$ (atmospheric pressure) with a $1 \mathrm{M} \mathrm{KOH}$ electrolyte and at a solution flow velocity of $0.3 \mathrm{~m} \mathrm{~s}^{-1}$ for forced convection.

\subsection{Optical measurements}

The against-the-light photography has been applied to picture the hydrogen and oxygen bubbles present on an optically transparent nickel electrode. For both electrolysis cells the experimental set-ups for taking pictures are schematically represented in Figs 1 and 2.

The optical system consists of a mercury arc $1 \mathrm{~A}$ (Oriel-HBO $100 \mathrm{~W} / 2$, arcsize $0.25 \times 0.25 \mathrm{~mm}^{2}$ ), a lens to focus the light beam, a microscope objective (no ocular has been used) and a high speed film camera (Hitachi, type: NAC 16D). The magnification can easily be varied by using another objective or by varying the distance between the objective and the camera. Picture frequencies up to 2000 frames pers were used to obtain sharply pictured bubbles. For every optical configuration, a graduated scale $11 \mathrm{~mm}$, divided in 100 equal parts) is recorded at the location of the working electrode, in order to determine the magnification factor. Light marks on the edge of the film, initiatcd by the film camera every 1,10 or $100 \mathrm{~ms}$, indicate the framing frequency. The bubbles on every single picture of the film can be visualized on the screen of a motion analyser (Hitachi, type: NAC MC. 

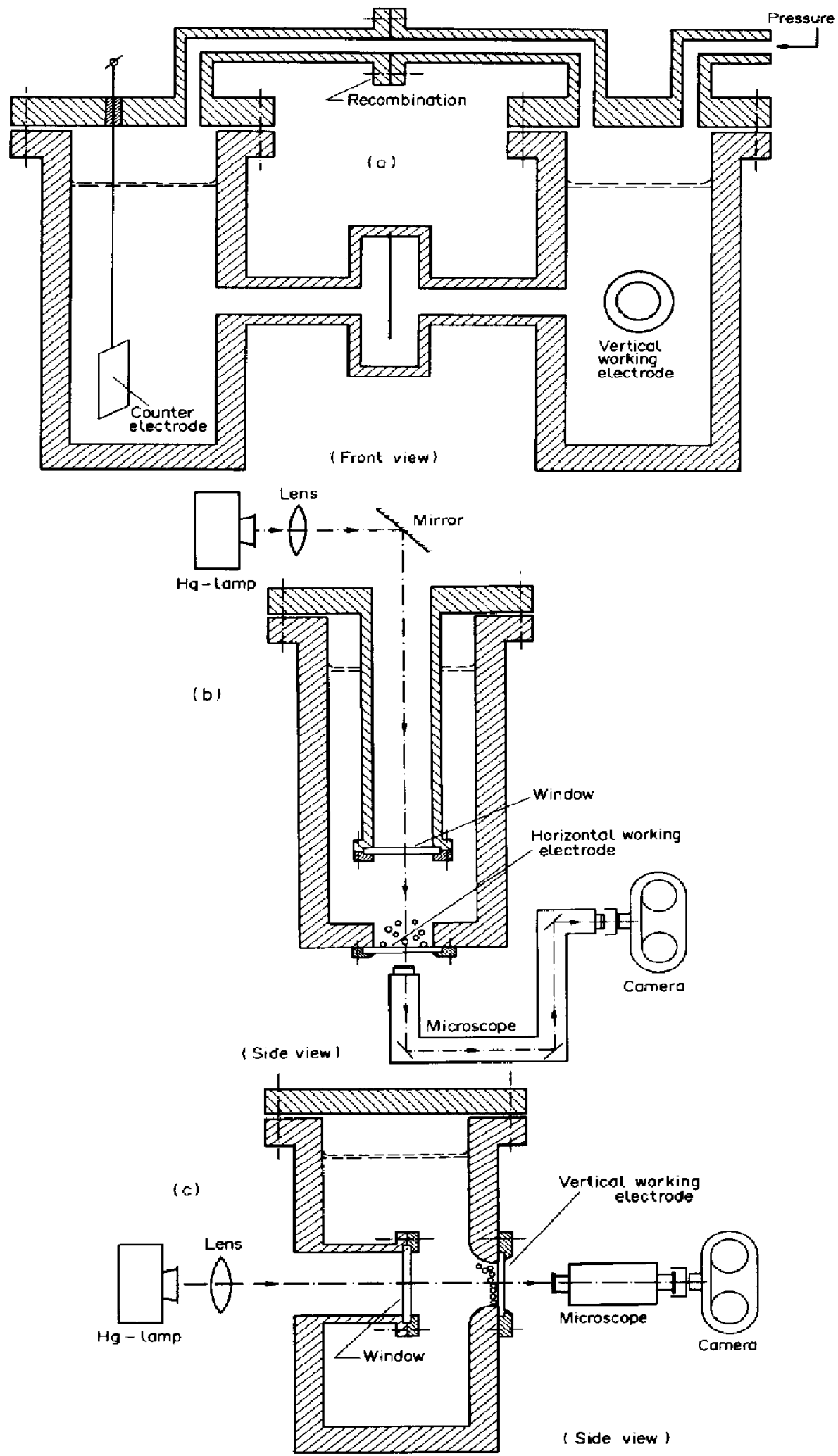

Fig. 2. Stainless steel electrolysis cell: (a) front view, (b) side view with horizontal electrode and (c) side vicw with vertical electrode. 
$\mathrm{OB} / \mathrm{PH}-160 \mathrm{~B})$. The size of every bubble on this screen can be measured and recorded on magnetic tape. The magnification is obtained by measuring the matching graduated scale. Data handling is performed by the university computer system (Burroughs 7700). With a computer programme various bubble quantities, such as size, gas volume fraction, distribution curves, can be obtained and easily averaged over one or more pictures.

\section{RESULTS}

\subsection{Description of bubble behaviour}

The behaviour of bubbles at the electrode surface shows fluctuations around a quasi-stationary state. The quasi-stationary state changes slowly at increasing time of electrolysis. The time scale of the fluctuation of bubble behaviour is some orders of magnitude smaller than the scale at which the quasi-stationary state changes.

At each instant, bubbles originating from different cavities, are in different stages of the growth process. Consequently, both the number and size of the attached bubbles vary in time. It has been observed that bubbles leaving their originating cavities without departing from the electrode surface slip across the electrode surface. They collide with other attached bubbles and new bubbles are formed by coalescence of the colliding bubbles. The newly formed bubbles either depart from the electrode surface or slip further across the electrode surface. They leave behind bubble-free tracks on the electrode surface. Thereafter, on these tracks a burst occurs of freshly formed bubbles, after which the cycle is repeated.

At natural convection the slipping bubbles move mainly in vertical direction at a vertical electrode and randomly at a horizontal electrode. The direction of bubble slip depends on that of the electrolyte flow. In comparison with a horizontal electrode, much more significant and periodical fluctuations in the behaviour of bubbles occur at a vertical electrode.

The behaviour, as described above, concerns both hydrogen and oxygen evolution. Yet, some gradual differences between hydrogen and oxygen bubble behaviour exist. It is well-known that in alkaline solutions hydrogen bubbles do not coalesce as easily as oxygen bubbles do and that hydrogen bubbles are smaller than oxygen bubbles. Consequently, due to the different coalescence behaviour, ascending, slipping hydrogen bubbles do not swallow up attached bubbles as easily as oxygen bubbles do. Additionally, because of their small size, the sphere of infuence of hydrogen bubbles is less extended than the one of oxygen bubbles. These two phenomena result in less substantial fluctuations in the hydrogen bubble behaviour in comparison with oxygen.

Another remarkable difference between hydrogen and oxygen evolution is the occurrence of a layer of free hydrogen bubbles, gliding over the layer of attached hydrogen bubbles. The layer of the gliding bubbles hardly affects that of the attached bubbles. At the oxygen evolving electrode, such a phenomenon has not been observed. Consequently, for the hydrogen evolving electrode a clear distinction between adhered bubbles and free bubbles is difficult to make and on the other hand for the oxygen evolving electrode this distinction is very clear.

\subsection{Determination of bubble parameters}

In order to characterize the bubble behaviour, the following bubble quantities have been determined fom observations of an electrode surface area, $A_{i}$, with $N_{i}$ attached bubbles:

$d_{i} ; \quad$ bubble population density for picture $i ; d_{i}$ $\quad=N_{i} / A_{i}$,

$d$; average density of bubble population for $n$ pictures; $d=\Sigma_{i=1}^{n}, d_{i} / n$,

$\boldsymbol{R}_{a, i} ; \quad$ average radius of adhered bubbles for picture $i$ : the radius of an adhered bubble $j$ on picture $i$ is denoted by $\boldsymbol{R}_{i, j} ; \boldsymbol{R}_{a, i}=\boldsymbol{\Sigma}_{j=1}^{N_{1}} \boldsymbol{R}_{i, j} / \boldsymbol{N}_{i}$,

$R_{a}$; $\quad$ average radius of adhered bubbles for $n$ pictures; $R_{a}=\Sigma_{i=1}^{n} R_{i} / n$,

$\boldsymbol{R}_{a, m}$; average maximum radius of adhered bubbles;

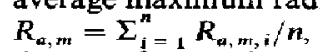

$s_{i}$; degree of screening of the electrode by attached bubbles for picture $i$; $i$ the fraction of the electrode surface, covered by projection of the bubbles; $s_{i}=\Sigma_{j=1}^{N_{i}} \pi R_{i, j}^{2} / A_{i}$,

$s$; average degree of screening of the electrode by attached bubbles; $s=\Sigma_{i=1}^{n} s_{i} / n$,

$V_{a, i} ;$ volume of attached spherical bubbles per unit surface area for picture $i ; V_{a, i}$ $=\sum_{j=1}^{N_{\mathrm{f}}} \frac{4}{3} \pi R_{i, j}^{3} / A_{i}$,

$V_{a}$; average volume of attached bubbles per unit surface area; $V_{a}=\Sigma_{i=1}^{n} V_{i} / n$.

At constant gas production rate the average bubble $R_{a}$ usually increases with decreasing $d$. It is likely that there is a strong relationship between these parameters. Analysing the experimental results, a new basic bubble parameter $J$ is proposed. This parameter is defined by $J=V_{a} d / s$. The basic bubble parameter $J$ is closely related to the parameter used, describing the mass transfer of indicator ions to an oxygen evolving electrode[1]. The parameter of [1] is equal to the average diameter of an adhered bubble at time of coalescence multiplied by the bubble population density on the electrode surface.

The bubble behaviour on a small electrode surface area was filmed during a certain period of time. The number of pictures of the film used to determine $d, R_{a}$, $s, V_{a}$ and $J$ depends on the fluctuation in the bubble behaviour and the number of bubbles on a picture. At least 10 pictures of $0.23 \mathrm{~mm}^{2}$ surface area, taken $50 \mathrm{~ms}$ after each other, were used determining the bubble parameters for oxygen evolution with the exception of the experiments with variation of pressure and electrolysis time. In the latter cases mostly three pictures of electrode surface area varying between 0.9 and $4.5 \mathrm{~mm}^{2}$ were observed.

For hydrogen evolution usually only four pictures of electrode surface area lying between 0.23 and $0.75 \mathrm{~mm}^{2}$ were used, because of the much higher bubble population density.

It has been found that the average bubble parameters obtained from about four subsequent pictures are practically equal to those obtained from 12 successive pictures. 


\subsection{Time of electrolysis}

The bubble population density on a transparent nickel electrode evolving oxygen decreases at a decreasing rate as a function of time of electrolysis [1]. New results are given in Fig. 3. The basic bubble parameter $J$, however, remains practically constant after electrolysis of about $60 \mathrm{~min}$. On the other hand, the other two parameters, viz the average density of bubble population and the average diameter of attached bubbles, change yet.

To obtain a reasonably constant electrode surface and to carry out complete series of experiments within a short period, series of experiments were usually started after $30 \mathrm{~min}$ of pre-electrolysis. Within a series of experiments the period between subsequent taking of pictures was usually $5 \mathrm{~min}$

\subsection{Current density}

The effect of current density has been determined at decreasing $i$ at free and forced convection, both for hydrogen and oxygen evolution. Only during hydrogen evolution, a layer of free bubbles glides over the layer of attached bubbles. Consequently, in this case, the determination of $d$ and $R_{a}$ is quite difficult.

For both hydrogen and oxygen evolving vertical electrodes in $1 \mathrm{M} \mathrm{KOH}$ at $303 \mathrm{~K}$ and $101 \mathrm{kPa}$ results are given in Table 1 for various current densities at free convection $\left(v=0 \mathrm{~ms} \mathrm{~s}^{-1}\right)$ and forced convection ( $v$ $=0.3 \mathrm{~ms}^{-1}$ ). Table 1 shows that for both hydrogen and oxygen evolution at both free and forced convection, $\boldsymbol{d}, \boldsymbol{R}_{a, m}, s, \boldsymbol{V}_{a}$ and $J$ increase with increasing $i$, and that $R_{a}$ decreases with increasing $i$.

Special attention is given to the basic bubble parameter $J$. This parameter is plotted $v$ s on a double logarithmic scale for an oxygen evolving electrode in Fig. 4 and for a hydrogen evolving electrode in Fig. 5.

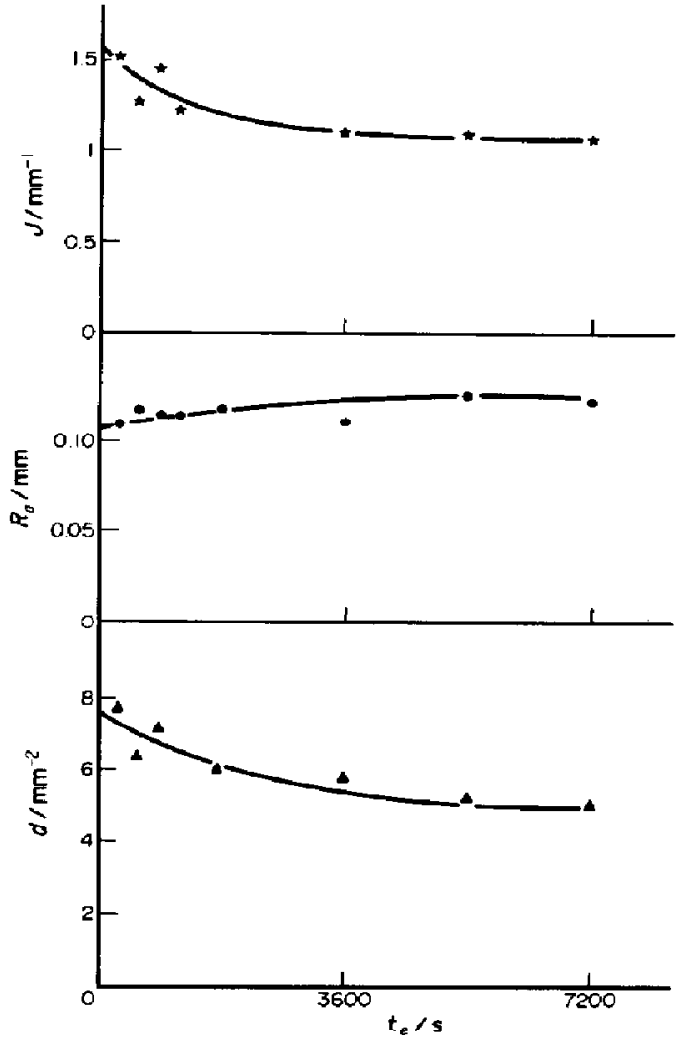

Fig. 3. Average bubble poputation density $d$, average bubble radius $\boldsymbol{R}_{a}$ and basic bubble parameter $\boldsymbol{J}$ are plotied $v$ s the electrolysis time for an oxygen evolving vertical electrode in $1 \mathrm{M} \mathrm{KOH}$, at $1.5 \mathrm{kA} \mathrm{m}^{-2}, 303 \mathrm{~K}, 101 \mathrm{kPa}$ and free convection.

Table 1. Effect of $i$ on $d, R_{a}, R_{a, m}, s, V_{a}$ and $J$ for an oxygen and a hydrogen evolving vertical transparent nickel electrode in $1 \mathrm{M} \mathrm{KOH}$, at $303 \mathrm{~K}, 101 \mathrm{kPa}$ and at free and forced convection

\begin{tabular}{|c|c|c|c|c|c|c|c|c|}
\hline Nature of gas & $i\left(\mathrm{kA} \mathrm{m}^{-2}\right)$ & $v\left(\mathrm{~m} \mathrm{~s}^{-1}\right)$ & $d\left[(\mathrm{~mm})^{-2}\right]$ & $R_{p}(\mu \mathrm{m})$ & $R_{a, m}(\mu m)$ & $s$ & $V_{a}(\mu \mathrm{m})$ & $J\left[(\mathrm{~mm})^{-1}\right]$ \\
\hline $\mathbf{O}_{2}$ & $\begin{array}{l}0.5 \\
1.0 \\
2.0 \\
3.0 \\
4.0 \\
5.0 \\
0.5 \\
1.0 \\
2.0 \\
3.0 \\
4.0 \\
5.0\end{array}$ & 0.3 & $\begin{array}{r}22 \\
40 \\
83 \\
121 \\
143 \\
175 \\
11 \\
39 \\
69 \\
92 \\
128 \\
113\end{array}$ & $\begin{array}{l}31 \\
28 \\
21 \\
27 \\
21 \\
22 \\
21 \\
29 \\
27 \\
23 \\
19 \\
23\end{array}$ & $\begin{array}{r}65 \\
80 \\
84 \\
110 \\
113 \\
95 \\
29 \\
57 \\
63 \\
86 \\
78 \\
92\end{array}$ & $\begin{array}{l}0.10 \\
0.18 \\
0.25 \\
0.43 \\
0.41 \\
0.46 \\
0.02 \\
0.13 \\
0.23 \\
0.28 \\
0.29 \\
0.34\end{array}$ & $\begin{array}{r}8.7 \\
18.4 \\
25.5 \\
51.0 \\
50.1 \\
48.3 \\
0.7 \\
7.6 \\
19.3 \\
26.1 \\
26.3 \\
37.4\end{array}$ & $\begin{array}{r}1.85 \\
4.00 \\
8.55 \\
14.16 \\
17.59 \\
18.20 \\
0.43 \\
2.26 \\
5.75 \\
8.50 \\
11.78 \\
12.60\end{array}$ \\
\hline $\mathbf{H}_{2}$ & $\begin{array}{l}0.25 \\
1.50 \\
1.00 \\
1.50 \\
0.25 \\
0.50 \\
1.00 \\
1.50 \\
2.00 \\
2.50\end{array}$ & $\begin{array}{l}0 \\
0.3\end{array}$ & $\begin{array}{r}42 \\
77 \\
453 \\
1918 \\
43 \\
37 \\
223 \\
1068 \\
2070 \\
3572\end{array}$ & $\begin{array}{c}32 \\
26 \\
15 \\
5.9 \\
13 \\
17 \\
12 \\
6.9 \\
5.9 \\
4.1\end{array}$ & $\begin{array}{l}70 \\
70 \\
85 \\
75 \\
22 \\
29 \\
36 \\
28 \\
34 \\
32\end{array}$ & $\begin{array}{l}0.22 \\
0.23 \\
0.59 \\
0.56 \\
0.03 \\
0.04 \\
0.16 \\
0.24 \\
0.38 \\
0.37\end{array}$ & $\begin{array}{r}17.7 \\
15.2 \\
37.4 \\
33.4 \\
0.6 \\
1.2 \\
4.9 \\
4.4 \\
8.4 \\
8.4\end{array}$ & $\begin{array}{r}3.39 \\
5.07 \\
28.80 \\
110.64 \\
1.01 \\
1.17 \\
7.20 \\
19.98 \\
46.22 \\
40.96\end{array}$ \\
\hline
\end{tabular}




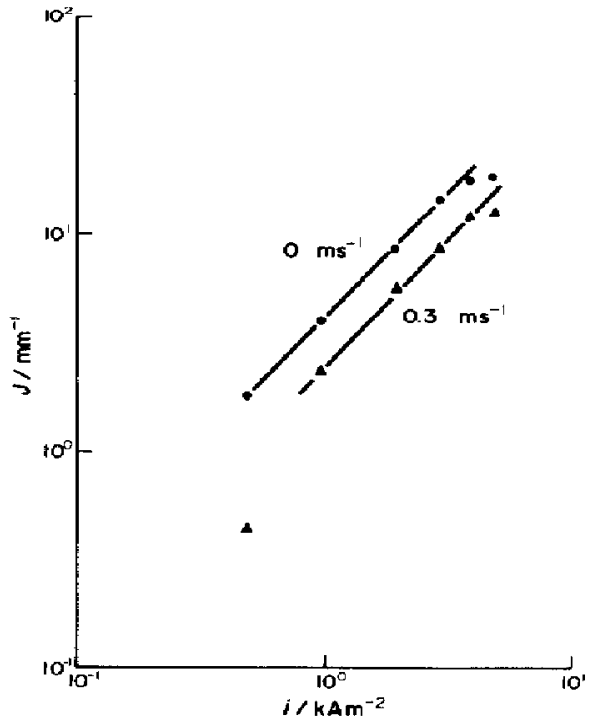

Fig. 4. Basic bubble parameter $J$ is plotted es the current density $i$ on a double logarithmic scale for an oxygen evolving vertical electrode in $1 \mathrm{M} \mathrm{KOH}$ and at $303 \mathrm{~K}, 101 \mathrm{kPa}$ free and forced convection $\left(v=0.3 \mathrm{~ms}^{-1}\right)$.

Figures 4 and 5 show that all the $\log J / \log i$ relations are linear. Only for the lowest current density a deviation occurs clearly. The slope $h_{i}$ of $\log J / \log i$ curve depends on the nature of gas evolved, but does not depend on the velocity of soution flow. The slope $h_{i}=1.15$ for oxygen evolving electrodes (Fig. 4) and 2.7 for hydrogen evolving electrodes (Fig. 5).

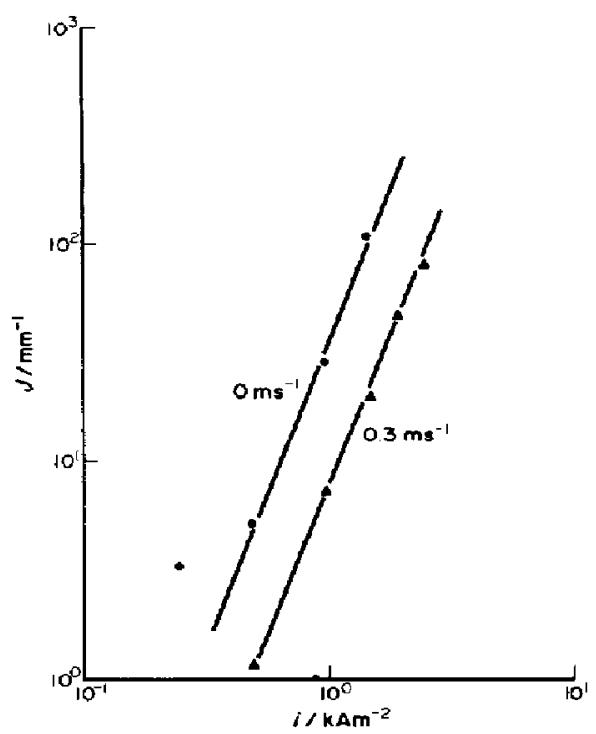

Fig. 5. Basic bubble parameter $J$ is plotted $v s$ the current density $i$ on a double logarithmic scale for a hydrogen evolving vertical electrode in $1 \mathrm{M} \mathrm{KOH}$ and at $303 \mathrm{~K}, 101 \mathrm{kPa}$ and free and forced convection $\left(b=0.3 \mathrm{~ms}^{-1}\right)$

\subsection{Solution flow velocity}

The effect of solution flow velocity, $v$, has been determined for series of experiments with decreasing $v$. For hydrogen evolution the experiments have been carried out at $2 \mathrm{kA} \mathrm{m}^{-2}$ and for oxygen evolution at two current densities, viz 2 and $5 \mathrm{kA} \mathrm{m}^{-2}$.

For both hydrogen and oxygen evolving vertical electrodes in $1 \mathrm{M} \mathrm{KOH}$ at $303 \mathrm{~K}$ and $101 \mathrm{kPa}$ results are given in Table 2 for various velocities of solution flow.

Table 2. Effect of $v$ on $d, R_{a}, R_{a, m}, s, V_{\alpha}$ and $J$ for an oxygen and a hydrogen evolving vertical transparent nickel electrode in $1 \mathrm{M} \mathrm{KOH}$, at $303 \mathrm{~K}, 101 \mathrm{kPa}$ and at two current densities

\begin{tabular}{|c|c|c|c|c|c|c|c|c|}
\hline Nature of gas & $i\left(\mathrm{kA} \mathrm{m}^{-2}\right)$ & $v\left(\mathrm{~ms}^{-1}\right)$ & $d\left[(\mathbf{m m})^{-2}\right]$ & $R_{a}(\mu \mathrm{m})$ & $\boldsymbol{R}_{a, m}(\mu \mathrm{m})$ & $s$ & $V_{a}(\mu \mathrm{m})$ & $J\left[(\mathrm{~mm})^{-1}\right]$ \\
\hline $\mathrm{O}_{2}$ & 2 & $\begin{array}{l}0 \\
0.1 \\
0.2 \\
0.3 \\
0.4 \\
0.5 \\
0.75 \\
1.0\end{array}$ & $\begin{array}{l}81 \\
62 \\
69 \\
61 \\
46 \\
46 \\
23 \\
24\end{array}$ & $\begin{array}{r}24 \\
29 \\
29 \\
22 \\
19 \\
14 \\
11 \\
9\end{array}$ & $\begin{array}{r}101 \\
88 \\
80 \\
55 \\
42 \\
24 \\
14 \\
12\end{array}$ & $\begin{array}{l}0.28 \\
0.28 \\
0.30 \\
0.15 \\
0.08 \\
0.04 \\
0.008 \\
0.006\end{array}$ & $\begin{array}{l}32.9 \\
27.4 \\
25.8 \\
9.2 \\
3.8 \\
1.1 \\
0.13 \\
0.087\end{array}$ & $\begin{array}{l}9.41 \\
6.14 \\
5.95 \\
3.85 \\
2.24 \\
1.40 \\
0.39 \\
0.35\end{array}$ \\
\hline & 5 & $\begin{array}{l}0 \\
0.1 \\
0.2 \\
0.3 \\
0.4 \\
0.5 \\
0.75 \\
1.0\end{array}$ & $\begin{array}{l}202 \\
254 \\
245 \\
258 \\
337 \\
396 \\
348 \\
313\end{array}$ & $\begin{array}{r}21 \\
17 \\
18 \\
16 \\
13 \\
10 \\
8 \\
8\end{array}$ & $\begin{array}{r}112 \\
95 \\
86 \\
81 \\
62 \\
40 \\
26 \\
24\end{array}$ & $\begin{array}{l}0.54 \\
0.41 \\
0.44 \\
0.43 \\
0.33 \\
0.20 \\
0.11 \\
0.09\end{array}$ & $\begin{array}{c}59.4 \\
40.9 \\
39.0 \\
34.9 \\
17.8 \\
6.9 \\
2.3 \\
1.81\end{array}$ & $\begin{array}{r}22.1 \\
25.6 \\
21.9 \\
20.5 \\
18.0 \\
13.8 \\
7.6 \\
6.3\end{array}$ \\
\hline $\mathbf{H}_{2}$ & 2 & $\begin{array}{l}0 \\
0.1 \\
0.2 \\
0.3 \\
0.4 \\
0.5 \\
0.75 \\
1.0\end{array}$ & $\begin{array}{r}903 \\
2020 \\
1153 \\
781 \\
628 \\
404 \\
300 \\
171\end{array}$ & $\begin{array}{l}8 \\
7 \\
8 \\
9 \\
8 \\
9 \\
6 \\
6\end{array}$ & $\begin{array}{l}61 \\
36 \\
48 \\
42 \\
31 \\
30 \\
14 \\
13\end{array}$ & $\begin{array}{l}0.40 \\
0.44 \\
0.36 \\
0.30 \\
0.19 \\
0.14 \\
0.04 \\
0.02\end{array}$ & $\begin{array}{r}25.79 \\
9.88 \\
10.30 \\
8.06 \\
4.43 \\
3.01 \\
0.50 \\
0.23\end{array}$ & $\begin{array}{r}58.2 \\
45.9 \\
32.0 \\
21.3 \\
14.9 \\
8.6 \\
3.7 \\
1.9\end{array}$ \\
\hline
\end{tabular}


In general $d, R_{a}, R_{a, m}, s, V_{a}$ and $J$ decrease with increasing velocity of solution flow. It is very likely that this effect is relatively small at a high current density, eg $5 \mathrm{kA} \mathrm{m}^{-2}$, and a low velocity of solution flow, eg $0.1 \mathrm{~ms}^{-1}$.

Plotting $J$ vs $v$ and extrapolating $J$ to $v=0 \mathrm{~m} \mathrm{~s}^{-1}$, $J_{0}$, is obtained. From the results of Table 2 it can be shown that for oxygen evolution $J_{0}=8 \mathrm{~mm}^{-1}$ at $2 \mathrm{kA} \mathrm{m}^{-2}$ and $23 \mathrm{~mm}^{-1}$ at $5 \mathrm{kA} \mathrm{m}^{-2}$, and for hydrogen evolution $J_{0}=60 \mathrm{~mm}^{-1}$ at $2 \mathrm{kA} \mathrm{m}^{-2}$. To describe the dependence of the basic bubble parameter $J$ on $v$, the term $J /\left(J_{0}-J\right)$ is plotted $v s v$ on a double logarithmic scale as presented in Fig. 6 for oxygen evolution at 2 and $5 \mathrm{kA} \mathrm{m}^{-2}$ and for hydrogen evolution at $2 \mathrm{kA} \mathrm{m}^{-2}$.

Figure 6 shows that $\log \left(J /\left(J_{0}-J\right)\right.$ decreases linearly with increasing velocity of solution flow; its slope $h_{2}$ does not depend on both current density and nature of gas evolved and is equal to -2.9 .

\subsection{Pressure}

The effect of pressure has been studied at only free convection for both oxygen and hydrogen evolving vertical electrodes and for oxygen evolving horizontal electrodes. The experiments have been carried out in the sequence of decreasing pressure.

Results are given in Table 3 for gas evolution with $2 \mathrm{kA} \mathrm{m}^{-2}$ in $1 \mathrm{MKOH}$ at $303 \mathrm{~K}$. This table shows

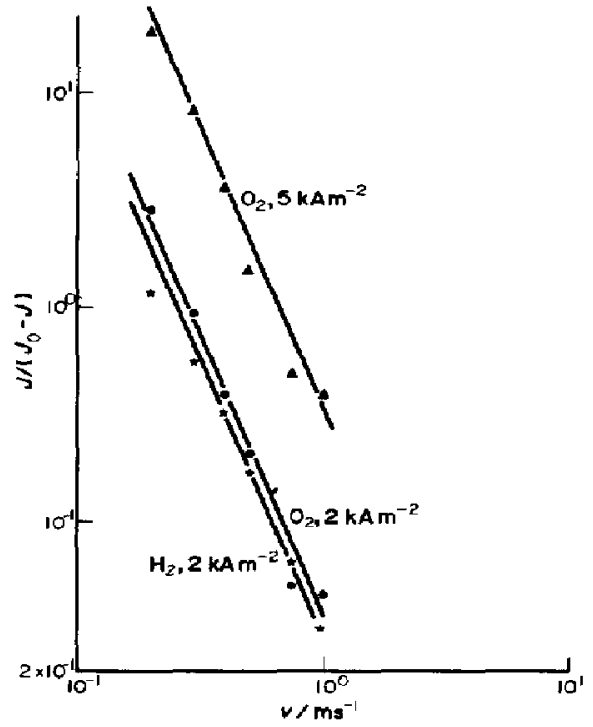

Fig. 6. $J /\left(J_{0}-J\right)$ is platted $v$ s the velocity of solution on a double logarithmic scale for an oxygen evolving vertical electrode in $1 \mathrm{M} \mathrm{KOH}$, at 2 and $5 \mathrm{kA} \mathrm{m}^{-2}, 303 \mathrm{~K}$ and $101 \mathrm{kPa}$ and for a hydrogen evolving vertical electrode in $1 \mathrm{M} \mathrm{KOH}$ and at $2 \mathrm{kA} \mathrm{m}^{-2}, 303 \mathrm{~K}$ and $101 \mathrm{kPa}$.

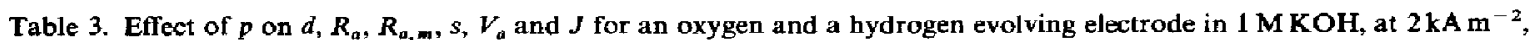
$303 \mathrm{~K}$, free convection ( $v=0 \mathrm{~m} \mathrm{~s}^{-1}$ ) and at horizontal and vertical position of electrode

\begin{tabular}{|c|c|c|c|c|c|c|c|c|}
\hline Nature of gas & $\begin{array}{l}\text { Position of } \\
\text { electrode }\end{array}$ & $p(\mathbf{k P a})$ & $d\left[(\mathrm{~mm})^{-2}\right]$ & $R_{a}(\mu \mathrm{m})$ & $R_{a, m}(\mu \mathrm{m})$ & $s$ & $V_{a}(\mu \mathrm{m})$ & $J\left[(\mathrm{~mm})^{-1}\right]$ \\
\hline \multirow[t]{2}{*}{$\mathrm{O}_{2}$} & Vertical & $\begin{array}{r}50 \\
75 \\
101 \\
253 \\
505 \\
1010 \\
1515 \\
2020 \\
2525 \\
3030\end{array}$ & $\begin{array}{r}28 \\
42 \\
64 \\
131 \\
167 \\
220 \\
223 \\
283 \\
316 \\
408\end{array}$ & $\begin{array}{l}79 \\
63 \\
48 \\
25 \\
17 \\
13 \\
12 \\
11 \\
9.3 \\
8.7\end{array}$ & $\begin{array}{r}143 \\
129 \\
114 \\
84.8 \\
85.5 \\
75.3 \\
71.8 \\
48.5 \\
44.8 \\
41.8\end{array}$ & $\begin{array}{l}0.57 \\
0.51 \\
0.56 \\
0.32 \\
0.22 \\
0.16 \\
0.14 \\
0.14 \\
0.11 \\
0.12\end{array}$ & $\begin{array}{r}93.9 \\
70.2 \\
58.6 \\
22.4 \\
10.4 \\
7.0 \\
5.6 \\
3.5 \\
2.5 \\
2.3\end{array}$ & $\begin{array}{l}4.60 \\
5.75 \\
6.67 \\
9.06 \\
7.77 \\
9.52 \\
8.64 \\
7.27 \\
6.92 \\
7.60\end{array}$ \\
\hline & Horizontal & $\begin{array}{r}25 \\
50 \\
75 \\
101 \\
253 \\
505 \\
1010 \\
1515 \\
2020 \\
2525 \\
3030\end{array}$ & $\begin{array}{c}6.1 \\
9.2 \\
13 \\
14 \\
27 \\
52 \\
94 \\
117 \\
148 \\
136 \\
135\end{array}$ & $\begin{array}{r}133 \\
108 \\
94 \\
86 \\
60 \\
34 \\
23 \\
20 \\
17 \\
16 \\
16\end{array}$ & $\begin{array}{r}206 \\
168 \\
172 \\
138 \\
118 \\
81 \\
63 \\
47 \\
37 \\
36 \\
36\end{array}$ & $\begin{array}{l}0.38 \\
0.39 \\
0.44 \\
0.36 \\
0.37 \\
0.23 \\
0.18 \\
0.16 \\
0.15 \\
0.12 \\
0.11\end{array}$ & $\begin{array}{r}84.8 \\
71.2 \\
71.2 \\
51.1 \\
40.9 \\
15.4 \\
7.5 \\
5.4 \\
4.1 \\
3.1 \\
2.8\end{array}$ & $\begin{array}{l}1.35 \\
1.70 \\
2.15 \\
1.94 \\
2.97 \\
3.49 \\
3.93 \\
3.90 \\
4.18 \\
3.55 \\
3.45\end{array}$ \\
\hline $\mathbf{H}_{2}$ & Vertical & $\begin{array}{r}25 \\
50 \\
75 \\
101 \\
253 \\
505 \\
1010 \\
1515 \\
2020 \\
2525 \\
3030\end{array}$ & $\begin{array}{l}261 \\
236 \\
310 \\
341 \\
501 \\
561 \\
681 \\
703 \\
876 \\
761 \\
773\end{array}$ & $\begin{array}{r}13.6 \\
12.2 \\
12.4 \\
9.9 \\
7.7 \\
7.2 \\
6.5 \\
5.5 \\
5.5 \\
5.4 \\
4.8\end{array}$ & $\begin{array}{l}45.6 \\
26.1 \\
33.7 \\
24.0 \\
22.4 \\
25.7 \\
12.6 \\
11.0 \\
10.1 \\
12.7 \\
10.3\end{array}$ & $\begin{array}{l}0.26 \\
0.13 \\
0.18 \\
0.13 \\
0.11 \\
0.10 \\
0.10 \\
0.07 \\
0.09 \\
0.08 \\
0.06\end{array}$ & $\begin{array}{l}8.2 \\
2.9 \\
4.3 \\
2.3 \\
1.5 \\
1.3 \\
1.0 \\
0.61 \\
0.77 \\
0.65 \\
0.46\end{array}$ & $\begin{array}{l}8.34 \\
5.21 \\
7.35 \\
6.26 \\
6.87 \\
7.17 \\
6.78 \\
5.89 \\
7.48 \\
6.47 \\
5.82\end{array}$ \\
\hline
\end{tabular}




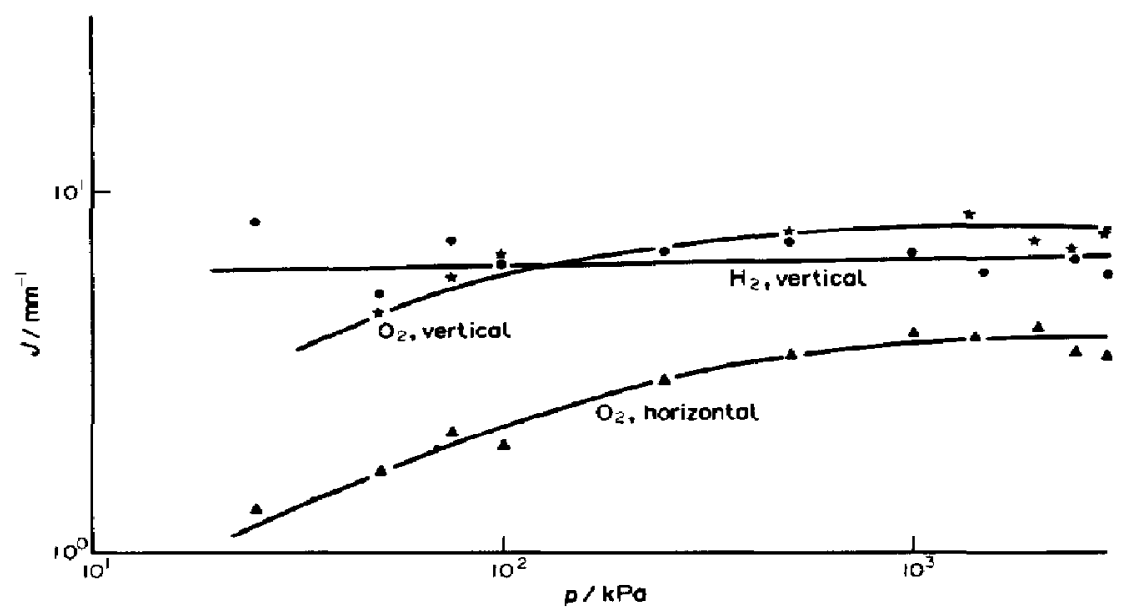

Fig. 7. Basic bubble parameter $J$ is plotted $v$ s pressure in electrolysis cell on a double logarithmic scale for a hydrogen evolving vertical electrode and for an oxygen evolving vertical and horizontal electrode in $1 \mathrm{M} \mathrm{KOH}$, at $2 \mathrm{kA} \mathrm{m}^{-2}, 303 \mathrm{~K}$ and free convection.

clearly that $d$ and $J$ increases and $R_{a}, R_{a, m}, S$ and $V_{a}$ decrease with increasing pressure for both positions of electrodes and for both gases evolved. The basic bubble parameter $J$ is plotted $v s p$ in Fig. 7 on a double logarithmic scale. Figure 7 shows that for oxygen evolution $J$ increases in a decreasing rate with increasing pressure and approximates a constant value at pressures higher than $505 \mathrm{kPa}$. The shape of the $\log J / \log p$ for a vertical electrode equals that for a horizontal electrode. For hydrogen evolution $J$ does not depend on pressure.

\subsection{Temperature}

The experiments on the effect of temperature have been carried out only for oxygen evolving vertical electrodes at free and forced convection $\left(0.3 \mathrm{~m} \mathrm{~s}^{-1}\right)$. At free convection, experiments have been carried out at increasing and decreasing temperature, and at forced convection only at increasing temperature. The experimental results given in Table 4 for both types of convection are given in the sequence of performance.
The experiments have been carried out in $1 \mathrm{M} \mathrm{KOH}$, at

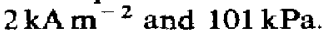

Table 4 shows a small effect of hysteresis and, generally, a decrease of $d, s, V_{a}$ and $J$ with increasing temperature and practically no effect of temperature on $R_{a}$ and $R_{a, m}$ at free convection.

In Fig. $8 \log J$ is plotted $v s T^{-1}$ for oxygen evolution at free and forced convection. This figure shows that the temperature effect on $J$ is much stronger for forced convection than for free convection.

\section{8. $\mathrm{KOH}$ concentration}

The bubble behaviour at various $\mathrm{KOH}$ concentrations has been investigated for vertical electrodes at free (hydrogen and oxygen evolution) and at forced convection (only oxygen evolution). The experiments have been carried out with increasing $\mathrm{KOH}$ concentration; after each experiment the electrolyte has been changed. Results are given in Table S. This table shows that $d, s, V_{a}$ and $J$ increase with increasing $\mathbf{K O H}$ concentration and, on the other hand, $\boldsymbol{R}_{a}$ and $\boldsymbol{R}_{a, m}$

Table 4. Effect of $T$ on $d, R_{a}, R_{a, m}, s, V_{a}$ and $J$ for an oxygen evolving vertical transparent nickel electrode in $1 \mathrm{M} \mathrm{KOH}$ and at $2 \mathrm{kA} \mathrm{m}^{-2}, 101 \mathrm{kPa}$ and at free and forced convection

\begin{tabular}{|c|c|c|c|c|c|c|c|}
\hline$v\left(\mathrm{~ms} \mathrm{~s}^{-1}\right)$ & $T(\mathbf{K})$ & $d\left[(\mathrm{~mm})^{-2}\right]$ & $R_{\mathrm{a}}(\mu \mathrm{m})$ & $R_{a, m}(\mu \mathrm{m})$ & $s$ & $V_{a}(\mu \mathrm{m})$ & $J\left[(\mathrm{~mm})^{-1}\right]$ \\
\hline 0 & $\begin{array}{l}297 \\
303 \\
318 \\
333 \\
353 \\
333 \\
318 \\
303\end{array}$ & $\begin{array}{l}148 \\
152 \\
172 \\
107 \\
116 \\
157 \\
161 \\
157\end{array}$ & $\begin{array}{l}18 \\
17 \\
14 \\
18 \\
20 \\
21 \\
21 \\
22\end{array}$ & $\begin{array}{l}85 \\
83 \\
77 \\
78 \\
81 \\
67 \\
78 \\
56\end{array}$ & $\begin{array}{l}0.30 \\
0.31 \\
0.25 \\
0.22 \\
0.27 \\
0.30 \\
0.25 \\
0.30\end{array}$ & $\begin{array}{l}28.2 \\
27.6 \\
17.9 \\
18.3 \\
20.9 \\
16.4 \\
14.8 \\
14.3\end{array}$ & $\begin{array}{r}13.9 \\
13.7 \\
12.3 \\
8.9 \\
9.1 \\
9.6 \\
9.7 \\
10.6\end{array}$ \\
\hline 0.3 & $\begin{array}{l}297 \\
303 \\
318 \\
333 \\
353\end{array}$ & $\begin{array}{l}179 \\
169 \\
164 \\
114 \\
102\end{array}$ & $\begin{array}{l}13 \\
16 \\
10 \\
13 \\
10\end{array}$ & $\begin{array}{l}53 \\
57 \\
42 \\
32 \\
25\end{array}$ & $\begin{array}{l}0.18 \\
0.25 \\
0.11 \\
0.10 \\
0.05\end{array}$ & $\begin{array}{r}9.2 \\
13.0 \\
4.5 \\
3.8 \\
1.3\end{array}$ & $\begin{array}{l}9.18 \\
8.84 \\
6.67 \\
4.41 \\
2.53\end{array}$ \\
\hline
\end{tabular}




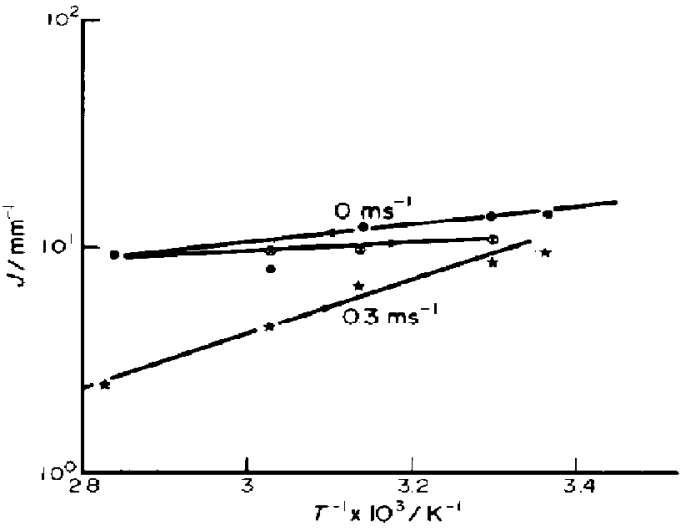

Fig. 8. The logarithm of basic bubble parameter $J$ is plotted vs the reciprocal of absolute temperature for an oxygen evolving vertical electrode in $1 \mathrm{M} \mathrm{KOH}$ and at $2 \mathrm{kA} \mathrm{m}^{-2}$,

$101 \mathrm{kPa}$ and free and forced convection $\left(v=0.3 \mathrm{~m} \mathrm{~s}^{-1}\right)$.

decrease with increasing $\mathrm{KOH}$ concentration.

Figure 9 shows the effect of $\mathrm{KOH}$ concentration on the basic bubble parameter $J$. The velocity of solution flow has practically no effect on the shape of $\log J / \mathrm{log}$ $[\mathrm{KOH}]$ curve. The effect of $\mathrm{KOH}$ concentration on $J$ for oxygen evolution is much greater than that for hydrogen evolution.

\section{DISCUSSION}

A gas-evolving electrode is an electrode on which bubble formation occurs. The formed gas is transferred to the bulk of solution by bubbles departing from the electrode surface as well as by diffusion and

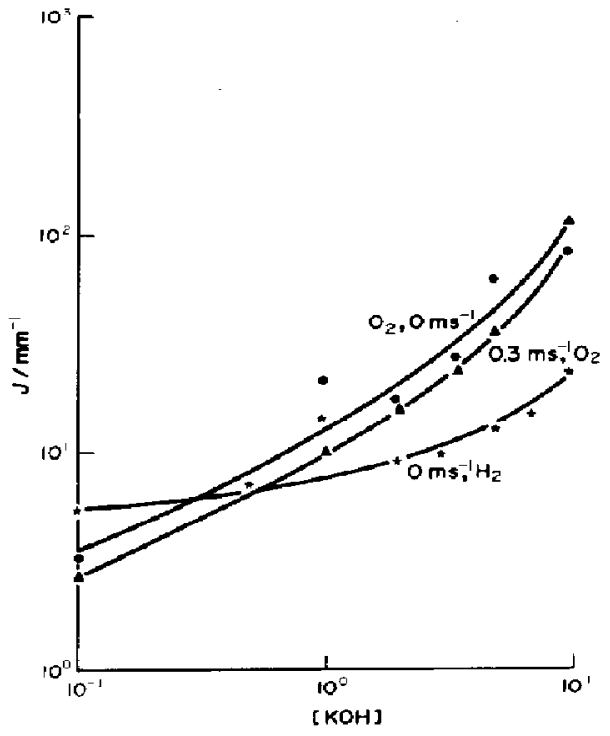

Fig. 9. Basic bubble parameter $J$ is plotted us KOH concentration on a double logarithmic scale for an oxygen and a hydrogen evolving vertical electrode at $1 \mathrm{kA} \mathrm{m}^{-2}, 303 \mathrm{~K}$, $101 \mathrm{kPa}$ and free convection.

convection of dissolved gas. During bubble formation the supersaturation at electrode and the transfer rate of dissolved gas to the bulk of solution depend on many factors, $e g$ flow of solution, rate of formation of gas, population density of attached bubbles; growth rate of bubbles and size of detached bubbles. Many of these factors affect each other. Consequently, there will be no simple relation for the ratio of the rate of quantity of gas transferred by bubbles to that transferred by

Table 5. Effect of $\mathrm{KOH}$ concentration on $d, R_{a}, R_{a, m}, s, V_{a}$ and $J$ for an oxygen evolving vertical transparent nickel electrode at $2 \mathrm{kA} \mathrm{m}^{-2}, 303 \mathrm{~K}, 101 \mathrm{kPa}$ and free and forced convection and for a hyarogen evolving vertical transparent electrode at $1 \mathrm{kA} \mathrm{m}^{-2}, 303 \mathrm{~K}, 101 \mathrm{kPa}$ and free convection

\begin{tabular}{|c|c|c|c|c|c|c|c|c|}
\hline $\begin{array}{l}\text { Naturc of gas } \\
\text { evolved }\end{array}$ & $v\left(\mathrm{~ms} \mathrm{~s}^{-1}\right)$ & {$[\mathrm{KOH}](\mathrm{M})$} & $d\left[(\mathrm{~mm})^{-2}\right]$ & $R_{\alpha}(\mu \mathrm{m})$ & $\boldsymbol{K}_{v, m}(\mu \mathrm{m})$ & $s$ & $V_{a}(\mu \mathrm{m})$ & $J\left[(\mathrm{~mm}){ }^{1}\right]$ \\
\hline \multirow[t]{12}{*}{$\mathrm{O}_{2}$} & 0 & 0.1 & 27 & 30.3 & 101 & 0.13 & 15.9 & 3.24 \\
\hline & & 1.0 & 251 & 12.8 & 74 & 0.28 & 22.9 & 20.9 \\
\hline & & 2.0 & 250 & 13.6 & 75 & 0.28 & 19.5 & 17.2 \\
\hline & & 3.5 & 367 & 12.0 & 77 & 0.39 & 29.5 & 27.8 \\
\hline & & 5.0 & 637 & 7.5 & 76 & 0.39 & 37.9 & 62.0 \\
\hline & & 7.0 & 1688 & 6.8 & 52 & 0.60 & 29.3 & 83.0 \\
\hline & 0.3 & 0.1 & 35 & 20.6 & 70 & 0.08 & 6.1 & 2.67 \\
\hline & & 1.0 & 267 & 11.1 & 40 & 0.17 & 6.3 & 9.99 \\
\hline & & 2.0 & 282 & 12.0 & 60 & 0.24 & 13.1 & 15.5 \\
\hline & & 3.5 & 446 & 9.5 & 62 & 0.29 & 15.2 & 23.4 \\
\hline & & 5.0 & 914 & 5.7 & 46 & 0.21 & 8.1 & 35.8 \\
\hline & & 7.0 & 2294 & 5.8 & 41 & 0.26 & 14.6 & 12.6 \\
\hline \multirow[t]{8}{*}{$\mathbf{H}_{2}$} & 0 & 0.1 & 69 & 22.7 & 92 & 0.21 & 16.30 & 5.48 \\
\hline & & 0.5 & 174 & 11.9 & 56 & 0.13 & 5.31 & 7.00 \\
\hline & & 1.0 & 395 & 9.1 & 42 & 0.16 & 5.82 & 14.10 \\
\hline & & 2.0 & 415 & 10.6 & 25 & 0.19 & 4.00 & 8.97 \\
\hline & & 3.0 & 323 & 13.8 & 33 & 0.26 & 7.58 & 9.60 \\
\hline & & 5.0 & 520 & 10.2 & 33 & 0.22 & 5.42 & 12.58 \\
\hline & & 7.0 & 1038 & 7.3 & 24 & 0.26 & 3.71 & 14.93 \\
\hline & & 10.0 & 1605 & 5.3 & 22 & 0.20 & 2.93 & 23.17 \\
\hline
\end{tabular}


mass diffusion and convection. When no bubble formation occurs, all the formed gas is transferred to the bulk of solution by mass diffusion and convection. It is likely that the contribution of bubbles to transfer of gas increases with increasing rate of gas formation and with decreasing velocity of solution flow.

Deviations in the $\operatorname{lng} . J / \log i$ curves from the straight solid lines occur at the lowest current density, in particular at forced convection with $v=0.3 \mathrm{~m} \mathrm{~s}^{-1}$ (Fig. 4). Assuming a linear relation between $\log J$ and $\log i_{b}$, where $i_{b}$ is the current density used for production of gas taken up by bubbles present on the electrode surface, from Fig, 4 it can be estimated that $i_{\mathbf{h}}$ $=0.15 \mathrm{kA} \mathrm{m}^{-2}$ and $i_{d}=0.35 \mathrm{kA} \mathrm{m}^{-2}$ for oxygen evolving at $i=0.5 \mathrm{kA} \mathrm{m}^{-2}$ and forced convection with $v$ $=0.3 \mathrm{~ms}^{-1}$. The symbol $i_{d}$ indicates the rate of transfer of dissolved oxygen by diffusion and convection to the bulk of solution. For an oxygen evolving electrode in $1 \mathrm{M} \mathrm{KOH}$ and at $i=0.5 \mathrm{kA} \mathrm{m}^{-2}, 303 \mathrm{~K}$, $101 \mathrm{kPa}$ and $v=0.3 \mathrm{~m} \mathrm{~s}^{-1}$, the mass transfer coefficient $k$ for $\mathrm{Fe}(\mathrm{CN})_{6}^{4-}$ is $10^{-4} \mathrm{~m} \mathrm{~s}^{-1}$ [5]. Since $k$ is proportional to $D^{0.5}$ for an oxygen evolving electrode at free convection[1] and assuming the same proportionality at forced convection, from the diffusion coefficients of oxygen [6] and $\mathrm{Fe}(\mathrm{CN})_{6}^{4-}[1]$ it follows that $k_{0,}=1.5 k_{\mathrm{F}}$

From $i_{d}=350 \mathrm{~A} \mathrm{~m}^{-2}$ it follows that the flux density of dissolved oxygen is $9.1 \times 10^{-4} \mathrm{~mol} \mathrm{O}_{2} / \mathrm{m}^{2} \mathrm{~s}$. Since the supersaturation $C_{o}$ is the flux density divided by $k_{\mathrm{O}_{2}}$ calculation shows that the supersaturation $\Delta C_{O_{2}}$ $=6.07 \mathrm{~mol} \mathrm{~m}^{-3}$ for an oxygen evolving electrode in $1 \mathrm{MKOH}$ at $0.5 \mathrm{kAm}^{-2}, 303 \mathrm{~K}, 101 \mathrm{kPa}$ and $v$ $=0.3 \mathrm{~m} \mathrm{~s}^{-1}$. For oxygen evolution at a Pt electrode in $1 \mathrm{M} \mathrm{H}_{2} \mathrm{SO}_{4}$ at $298 \mathrm{~K}, 101 \mathrm{kPa}$ and $v=0 \mathrm{~m} \mathrm{~s}^{-1}$ Shibata[?] has found $\Delta C_{O_{2}}$ to be about $40 \mathrm{~mol} \mathrm{~m}^{-3}$. Much lower supersaturations than those obtained by Shibata have been calculated from bubble growth data by Vogt [8]. It is likely that the dependence of $J$ on $i$ can be strongly affected by transfer of gas by diffusion and convection, particularly at low current densities and high velocities of solution flow.

The slope $h_{1}$ being the slope of straights of Figs 4 and 5 does not depend on $v$, but depends on nature of gas evolved. The slope $h_{2}$ of $\log \left(J /\left(J_{0}-J\right)\right) / \log t$ curves is independent of nature of gas evolved and current density (Fig. 6).

From Figs $4-6$ it follows that for a vertical transparent nickel electrode in $1 \mathrm{M} \mathrm{KOH}$ and at $303 \mathrm{~K}$ and $101 \mathrm{kPa} n=1.07$ for oxygen evoution and $h_{1}=3.2$ for hydrogen evoluton and $h_{2}=-2.9$ for oxygen as well as for hydrogen evolution.

The effects of $\mathrm{KOH}$ concentration, temperature and pressure upon $J$ cannot be described by relatively simple relations, although for both gases an almost linear dependence of $\boldsymbol{J}$ on $\mathbf{K O H}$ concentration has been found (Fig. 9).

The effect of pressure depends on the nature of gas evolved; for hydrogen evolution $J$ is independent of the pressure at pressures from 25 to $3030 \mathrm{kPa}$ and for oxygen evolution $J$ increases with decreasing rate at increasing pressure and reaches practically a limit value at about $505 \mathrm{kPa}$. The shape of the $\log J / \log p$ curve is the same for the vertical and the horizontal working electrode. For oxygen evolution $J$ increases linearly with increasing reciprocal value of the absolute temperature but the slope of $\log J / T^{-1}$ curve increases with increasing velocity of solution, probably caused by an increase of transfer of dissolved oxygen by diffusion and convection at increasing temperature.

For various series of experiments the values of $J$ show a large spread. For instance, the experimental values of $J$ are $8.6,9.4,9.5,13.7,10.6$ and $20.7 \mathrm{~mm}^{-1}$ for an oxygen evolving vertical electrode in $1 \mathrm{M} \mathrm{KOH}$ at $2 \mathrm{kA} \mathrm{m}^{-2}, 303 \mathrm{~K}, 101 \mathrm{kPa}$ and at free convection. It can be concluded, that the reproducibility of the nature of oxygen evolving transparent nickel electrode is reasonable.

From the results given in Table 1 it can be shown that $J$ is about $0.80 d R_{a, m}$. Since $J=d V_{b} / s$, it follows that $V_{a} / s=0.80 \mathrm{R}_{a, m}$ - Consequently, $V_{a} / s$ is mainly determined by the big bubbles present on the electrode surface.

The ratio of the rate of gas evolution to $V_{a}$ can be considered to be an average replacement rate of the gas present on the electrode surface by newly formed gas. Evidently, this and the degree of screening of electrode surface by bubbles have to determine mass transfer of species to and away from the electrode surface.

The presence of gas bubbles on the electrode surface causes an increase of the ohmic resistance of the electrolyte layer, adjacent to the electrode surface. It can be shown that this resistance increase is closely related to $V_{a}$ and the bubbles departure radius[3]. These results are useful to elucidate the increase of ohmic resistance in an alkaline water electrolyser.

\section{REFERENCES}

1. L. J. J. Janssen and S. J. D. van Stralen, Electrochim. Acta 26, 1011 (1981).

2. H. Vogt, Fortschr. Verjahrungstechnik 20, 269 (1982).

3. C. W. M. P. Sillen, thesis, Eindhoven (1983).

4. L. J. J. Janssen, J. J. M. Geraets, E. Barendrecht and S. J. D.van Stralen, Electrochim. Acta 27, 1207 (1982).

5. L. J. J. Janssen, unpublished results.

6. F. T. B. J. van den Brink, thesis, Eindhoven (1981).

7. S. Shibata, Electrochim. Acta 23, 619 (1978).

8. H. Vogt, Electrochim. Acta 25, 527 (1980) 